\title{
BREVÍSSIMAS REFLEXÕES SOBRE A EVOLUÇÃO DO TRATAMENTO DA LITIGIOSIDADE REPETITIVA NO ORDENAMENTO BRASILEIRO, DO CPC DE 1973 AO CPC DE 2015
}

CONSIDERATIONS ON THE EVOLUTION OF REPETITIVE LITIGATION IN BRAZILIAN LAW, FROM THE 1973 CIVIL PROCEDURE CODE TO THE 2015 CIVIL PROCEDURE CODE

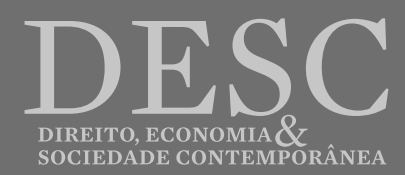




\title{
BREVÍSSIMAS REFLEXÕES SOBRE A EVOLUÇÃO DO TRATAMENTO DA LITIGIOSIDADE REPETITIVA NO ORDENAMENTO BRASILEIRO, DO CPC DE 1973 AO CPC DE 2015 ${ }^{1 *}$
}

\author{
CONSIDERATIONS ON THE EVOLUTION OF REPETITIVE \\ LITIGATION IN BRAZILIAN LAW, FROM THE 1973 CIVIL \\ PROCEDURE CODE TO THE 2015CIVIL PROCEDURE CODE
}

HEITOR VITOR MENDONÇA SICA

Universidade de São Paulo lattes.cnpq.br/3801088449482436 orcid.org/0000-0002-4861-8139 heitorsica@usp.br

\begin{abstract}
Resumo: O presente texto propõe-se a analisar a evolução do tratamento legislativo da litigiosidade repetitiva, do CPC de 1973 ao CPC de 2015, com especial ênfase ao microssistema de tutela coletiva e às reformas do ordenamento processual orientadas a introduzir mecanismos de aglomeração de processos individuais repetitivos.
\end{abstract}

Palavras-chave: tutela coletiva, litigiosidade repetitiva, incidente de resolução de demandasrepetitivas

\begin{abstract}
This paper analyzes the evolution of the legislative treatment of repetitive litigation, from the 1973 Brazilian civil procedure code to the 2015 Brazilian civil procedure code, with special emphasis on the collective redress microsystem and the reforms of the procedure code oriented to introduce mechanisms of agglomeration of repetitive individual processes.
\end{abstract}

Keywords: collective redress, repetitive litigiousness, incident of resolution of repetitive demands

\section{Introdução}

O CPC de 1973 declaradamente aspirava se revestir do mesmo apuro técnico que os Códigos de Processo Civil editados na Europa continental nas décadas anteriores, em especial o italiano e o português.

$1^{*} \mathrm{O}$ presente texto constitui versão revisada da exposição realizada em 26.11.2015 no Seminário Internacional "Sistemi processuali a confronto: il nuovo Codice di Procedura Civile del Brasilie, tra tradizione e rinnovamento", realizado em Roma, Itália, sob coordenação dos professores Bruno Sassani (Università "Tor Vergata"), Antonio Carratta (Università Roma Tre) e Giovanni Bonato (Univertè Paris Ouest Nanterre). Isso explica o teor descritivo de algumas passagens, particularmente importantes para o público estrangeiro, mas bem conhecidas pelos leitores brasileiros. 
Contudo, excetuado o aprimoramento terminológico, a melhor estruturação das matérias e alguns avanços pontuais, pode-se dizer que o CPC de 1973 era substancialmente igual ao diploma que o antecedeu (CPC de 1939²): ambos ainda fortemente arraigados às tradições herdadas do direito lusitano medieval ${ }^{3}$ e cunhados com o objetivo primordial a solução de conflitos intersubjetivos eclodidos em uma sociedade ainda majoritariamente rural. ${ }^{4}$

Não causa surpresa o fato de que rapidamente se concluiu que o CPC de 1973 era obsoleto e inadequado à solução de litígios complexos, que surgem em uma sociedade de massa urbana então em expansão.

À vista disso, o sistema processual civil passou, de $1980 \mathrm{em}$ diante, a ser profundamente alterado por numerosas e profundas reformas legislativas.

As dezenas de leis em matéria de direito processual civil editadas entre as décadas de 1980 e de 2000 podem ser subdivididas, para fins exclusivamente didáticos, em três grupos: (a) as que criaram e aprimoraram os mecanismos de tutela coletiva; (b) as que, posteriormente, reduziram a efetividade dos instrumentos de tutela coletiva antes criados; e (c) as que se propuseram a aprimorar os processos individuais.

\section{Criação do microssistema de processos coletivos (1985-1990).}

Entre 1985 e 1990, o Brasil promulgou dois diplomas que, analisados conjuntamente, formam um microssistema de processo coletivo: ${ }^{5}$ Leis Federais $n^{\circ} 7.347$ de 1985 e 8.078 de $1990 .{ }^{6}$

A primeira criou a chamada "ação civil pública", cujas características principais são as seguintes: (a) visa proteger direitos transindividuais ${ }^{7}$ que, até então, não eram tutelados pelos

2 Essa é a opinião de um dos maiores processualistas brasileiros de todos os tempos, Cândido Rangel Dinamarco (Instituições de direito processual civil.Vol. 1. $6^{\text {a }}$ ed. São Paulo: Malheiros, 2013, p.284-286).

3 Assim denunciou Liebman, em ensaio publicado após seu retorno a Itália: Istituti del diritto comune nel processo civile brasiliano. In: CARNELUTTI, Francesco. Studi in onore di Enrico Redenti, nel XL anno del suo insegnamento. Vol. 1. Milão: Giuffrè, 1951, p. 581-607.

4 Isso explica a profusão de procedimentos especiais e de mecanismos de intervenção de terceiros aplicáveis a litígios que envolviam posse e propriedade de imóveis, herdados de monumentos legislativos passados e afeiçoados a sociedades em que a terra é o principal bem de produção.

5 Afirmando a existência de um microssistema de tutela coletiva no ordenamento brasileiro, confira-se, por todos: GRINOVER, Ada Pellegrini. Direito processual coletivo. In: LUCON, Paulo Henrique dos Santos (coord.). Tutela coletiva. São Paulo: Atlas, 2006, p. 302-308.

6 Esses diplomas constituem os principais pilares do microssistema de tutela de interesses transindividuais, embora não tenham sido os primeiros a instituir normas nesse campo. Como bem lembrou há tempos Barbosa Moreira (A ação popular do direito brasileiro como instrumento de tutela jurisdicional dos chamados 'interesses difusos'. In: Temas de direito processual: primeira série. São Paulo: Saraiva, 1977, p.110-124), o ordenamento jurídico brasileiro previa a ação popular, há meio século disciplinada pela Lei $n^{\circ} 4.717 / 65$ e que já se apresentava como mecanismos de defesa de "interesses difusos", no tocante aos "bens e direitos de valor econômico, artístico, estético, histórico ou turístico" (art. $1^{\circ}$, par.ún., da Lei n 4.717/65). Contudo, a aplicabilidade desse instrumento era (e ainda é) limitada, pois deva abrigar o pedido de "anulação ou a declaração de nulidade de atos lesivos" (art. $1^{\circ}$, caput). Ou seja, fundamentalmente a ação popular é instrumento para ataque a atos administrativos (realidade reconhecida por Barbosa Moreira novamente alguns anos depois do ensaio aqui referido: A legitimação para a defesa dos 'interesses difusos' no direito brasileiro. In: Temas de direito processual: terceira série. São Paulo: Saraiva, 1984, p.186).

$7 \mathrm{O}$ art. $1^{\circ}$ da Lei $n^{\circ} 7.347$ se referia, originalmente, à tutela dos seguintes direitos transindividuais: meio-ambiente, relações de consumo, bens e direitos de valor artístico, estético, histórico, turístico e paisagístico. Posteriormente, incluíram-se por meio de reformas legislativas, a defesa da ordem urbanística e da ordem econômica. 
mecanismos individuais de tutela jurisdicional previstos no CPC de $1973 ;^{8}$ (b) legitimidade ativa concorrente e disjuntiva conferida ope legis a determinados entes públicos e privados reputados pela lei como representantes adequados; (c) o aprimoramento de mecanismos de efetivação da tutela específica (de modo a privilegiar a prevenção e a reparação in natura do direito transindividual lesado); ${ }^{9}$ (d) o estabelecimento de coisa julgada erga omnes secundum eventum probationis (isto é, coisa julgada ultra partes, ressalvada a possibilidade de repropositura da ação em caso de improcedência por insuficiência de provas). ${ }^{10}$

Em 1990, foi editado o Código de Defesa do Consumidor (CDC), que contém profunda normatização sobre tutela coletiva, não apenas relativa aos litígios consumeristas de massa, mas igualmente a todos os conflitos envolvendo quaisquer outros direitos transindividuais.

Além de diversos aprimoramentos em relação ao regime processual previsto na "Lei da Ação Civil Pública" de 1985, o CDC inovou ao possibilitar a tutela de direitos acidentalmente coletivos, os quais são direitos individuais com "impacto de massa" e que, portanto, podem ser tratados num processo coletivo. ${ }^{11} \mathrm{O}$ art. 81, parágrafo único, III do CDC os denominou, com claríssima inspiração na doutrina italiana, ${ }^{12}$ como direitos individuais homogêneos.

8 A criação desse subsistema partiu da constatação, feita décadas antes, de que determinados interesses, porquanto difusos
(rectius, pertencentes a uma gama indeterminável de titulares), não poderiam ser adequadamente tutelados pelos mecanismos
processuais cunhados pelo CPC de 1973 para litígios intersubjetivos, sobretudo face à restritiva regra concernente à legitimidade
ativa constante do seu art. $6^{\circ}$, primeira parte: "Ninguém poderá pleitear, em nome próprio, direito alheio (...)". Essa constatação
já era considerada pacífica no Brasil ao começo da década de 1980. Embora ocioso comprovar essa assertiva, não custa
mencionar a esse respeito Ada Pellegrini Grinover (Novas tendências na tutela jurisdicional dos interesses difusos. In: $O$
processo em sua unidade - II. Rio de Janeiro: Forense, 1984, p. $88-121$, esp. p. $96-118$ ). 9 Parte-se do correto pressuposto de que a tutela meramente reparatória no mais das vezes seria inócua para adequada proteção de determinados bens jurídicos, seja por seu valor inestimável, seja pela dificuldade ou impossibilidade prática de recuperá-los eficazmente depois de danificados.

10 A redação original do art. 16 da Lei $n^{\circ} 7.347$ era a seguinte: "A sentença civil fará coisa julgada erga omnes, exceto se a ação for julgada improcedente por deficiência de provas, hipótese em que qualquer legitimado poderá intentar outra ação com idêntico fundamento, valendo-se de nova prova".

11 Segundo entendimento doutrinário largamente disseminado, os direitos acidentalmente coletivos se diferenciam dos direitos essencialmente coletivos, os quais são divididos em duas categorias: os difusos e os coletivos em sentido estrito, os quais têm em comum, segundo Ricardo de Barros Leonel, "uma união tão firme que a satisfação de um só implica a satisfação de todo, e a lesão de um só implica a lesão da inteira coletividade. São os interesses essencialmente coletivos: o caráter coletivo é da própria essência, da substância do interesse". (Manual do processo coletivo. São Paulo: RT, 2002, p. 101-102). A par dessa expressão, já consagrada na doutrina, Teori Albino Zavascki preferiu se referir ao fenômeno como o de tutela coletiva de direitos individuais em contraposição à tutela de direitos coletivos (Processo coletivo. São Paulo: RT, 2006, cap.7).

12 Vicenzo Vigoriti, em 1979, já apresentava essa distinção entre os direitos difusos, coletivos e individuais homogêneos, assinalando que: "Non sarebbe peraltro, né oportuno di fronte a fenomeni suscenttibili di amplissimi svluppi, affermare che solo per certi interessi è possibile parlare di interessi diffusi o collettivi, e sostenere magari che gli interessi diffusi sono solo quelli che hanno un certo contenuto, e collettivi quelli che ne hanno uno ancora diverso. Le due formule concernono entrambe i processi di aggregazione degli interessi individuali ed indicano due stadi diversi di fenomeni omogenei nella sostanza. A livello semplicemente diffuso mandano i meccanismi di coordinamento delle volontà, non si sono saldati quei vincoli che possono dare un carattere unitario ad un fascio di interessi uguali; a livello collettivo esiste invece un'organizzazione, nel senso che esistono strumenti di direzione e di controllo, e la dimensione superindividuale degli interessi acquista una sua precisa rilevanza giuridica. (...) Questi scrive incisivamente che l'interesse collettivo è «l'interesse di una pluralità di persone a un bene idoneo a soddisfare un bisogno comune. Esso non à la somma di interessi individuali, ma la loro combinazione, ed è indivisible nel senso che viene soddisfatto non già da più beni atti a soddisfare i bisogni individuali, ma da un unico bene atto a soddisfare il bisogno della collettività»" (Interessi collettivi e processo: la legittimazione ad agire. Milão: Giuffrè, 1979, p. 43-47). Kazuo Watanabe, um dos autores do Anteprojeto de Código de Defesa do Consumidor, ao comentar o diploma apresentou a mesma distinção proposta por Vicenzo Vigoritti: “Os interesses ou direitos 'coletivos' foram conceituados como 'os transindividuais de natureza 
Imaginava-se que se trataria de um instrumento apto a neutralizar a litigiosidade repetitiva, ${ }^{13}$ promovendo isonomia no tratamento dos sujeitos individualmente afetados por condutas lesivas de projeção coletiva e diminuição da sobrecarga do Poder Judiciário com processos individuais oriundos do mesmo conflito de massa.

Em suma: parece claro que o objetivo de cada uma dessas técnicas de tutela coletiva é diverso. No primeiro caso, o foco é a ampliação do acesso à justiça, para a ela trazer litígios que não poderiam ser tratados por meio das técnicas de tutela individual. No segundo caso, o foco é a redução do acesso individual à justiça, substituindo-o pela tutela coletiva.

Ainda que sem embasamento em dados estatísticos, é corrente o pensamento de que a tutela dos direitos essencialmente coletivos apresentou resultados positivos e a tutela dos direitos acidentalmente coletivos malogrou.

No primeiro campo, de fato foi possível passar a trazer ao Poder Judiciário litígios que antes não eram judicializados com base nas técnicas processuais individualistas do CPC de 1973. Destaca-se, aí, particularmente o papel do Ministério Público, que se aparelhou de modo notável para a defesa de direitos transindividuais e assumiu verdadeiro protagonismo no sistema judiciário brasileiro, sobretudo nas áreas de proteção ao meio ambiente e à probidade administrativa.

No segundo campo, o sistema falhou nos intentos de reduzir a judicialização individual de litígios de massa repetitiva e de promover isonomia. E uma das explicações para tal fracasso repousa em uma diretriz colocada à base da tutela dos direitos acidentalmente coletivos, isto é, a de manter totalmente incólume o direito de acesso individual ao Poder Judiciário.

De fato, rechaçou-se tanto a técnica do opt-in quanto do opt-out, ${ }^{14}$ presente em outros

indivisível de que seja titular grupo, categoria ou classe de pessoas ligadas entre si ou com a parte contrária por uma relação jurídica de base' (art. 81, parágrafo, $\mathrm{n}^{\circ} \mathrm{II}$ ). Essa relação jurídica base é a preexistente à lesão ou ameaça de lesão do interesse ou direito do grupo, categoria ou classe de pessoas. Não a relação jurídica nascida da própria lesão ou da ameaça de lesão. (...) Nos interesses ou direitos 'difusos', a sua natureza indivisível e a inexistência de relação jurídica base não possibilitam, como já ficou visto, a determinação dos titulares. É claro que, num plano mais geral do fenômeno jurídico em análise, é sempre possível encontrar-se um vínculo que une as pessoas, como a nacionalidade. Mas a relação jurídica base que nos interessa na fixação dos conceitos em estudo, é aquela da qual é derivado o interesse tutelando, portanto interesse que guarda relação mais imediata e próxima com a lesão ou ameaça de lesão" E, nos interesses ou direitos individuais homogêneos, também poderá inexistir entre as pessoas uma relação jurídica base anterior. O que importa é que sejam todos os interesses individuais "decorrentes de origem comum'. O vínculo com a parte contrária é consequência da própria lesão" (Código brasileiro de defesa do consumidor comentado pelos autores do anteprojeto. $8^{\mathrm{a}}$ ed. Rio de Janeiro: Forense Universitária, 2005).

13 Neste sentido Ricardo de Barros Leonel apresentou claramente a finalidade dos direitos individuais homogêneos para solução da litigiosidade repetitiva, descrevendo que: "Neste contexto, podem ser identificadas vantagens na tutela coletiva dos interesses individuais homogêneos: prevenção da proliferação de numerosas demandas individuais onde se repetem exaustivamente o mesmo pedido e a mesma causa de pedir; obstar a contradição lógica de julgados, que desprestigia a justiça; resposta judiciária equânime e de melhor qualidade, com tratamento igual a situações análogas, conferindo efetividade à garantia constitucional da isonomia de todos perante a lei; alívio na sobrecarga do Poder Judiciário. Decorrente da 'atomização' de demandas que poderiam ser tratadas coletivamente; transporte útil da coisa julgada tirada no processo coletivo para demandas individuais" (Manual do processo coletivo. São Paulo: RT, 2002, p. 110).

14 Marcos Cavalcanti, de forma sucinta, descreve a funcionalidade da técnica do opt-ine opt-out no sistema estadunidense: "Após a efetiva notificação, o integrante da classe pode assumir as seguintes condutas: (a) requerer sua autoexclusão da lide (opt-out), dentro do prazo estabelecido, a fim de não ser alcançado pelos efeitos da coisa julgada material; (b) manter-se inerte e assumir os efeitos de decisão favorável ou desfavorável e da coisa julgada material (opt-in)" (Incidente de resolução de demandas repetitivas e ações coletivas. Salvador: Juspodivm, 2015, p. 94). 
sistemas de tutela coletiva e, no lugar disso, o art. 104 do CDC facultou ao autor da ação individual apenas a possibilidade de requerer a suspensão do seu processo, após ciência do ajuizamento da ação coletiva, sob penade não poder se beneficiar daeventual sentença de procedência lá proferida. Por outro lado, estabeleceu-se a coisa julgada erga omnes secundum eventum litis, de modo que os indivíduos somente se beneficiam da sentença de procedência, nunca se prejudicam (salvo no caso previsto no referido art. 104 do CDC). Assim, desponta evidente que o sistema não foi munido de instrumentos para inibir eficazmente demandas individuais, até mesmo porque, em um país de dimensões continentais, há natural dificuldade para que os sujeitos interessados tenham informação quanto à pendência de um processo coletivo.

Ademais, mesmo quando o sistema efetivamente funciona, substitui-se uma pluralidade de ações de conhecimento individuais por uma pluralidade de liquidações e execuções individuais da sentença coletiva genérica que julga procedente a ação coletiva que tutela direitos individuais homogêneos (art. 95, CDC).

Pois o sucesso do modelo detutela de direitos essencialmente coletivos e o fracasso do modelo de tutela dos direitos acidentalmente coletivos ajudam a explicar parte expressiva das reformas legislativas operadas no sistema processual nos anos 1990 e 2000 e, em alguma medida, as opções feitas na elaboração do CPC de 2015. Esse é o objeto da análise que se segue.

\section{Reformas do microssistema de processos coletivos (1992-2001)}

O segundo grupo de leis que reformaram o sistema processual civil brasileiro foram aquelas editadas entre 1992 e 2001, com o declarado propósito de enfraquecer o microssistema de processo coletivo, sobretudo relativamente à sua aplicação em face do Poder Público. ${ }^{15}$

Não bastasse, depois dessa época, naufragaram praticamente todas as iniciativas para reformas legislativas do microssistema de processos coletivos. ${ }^{16}$

O sistema processual civil brasileiro continuou, portanto, calcado essencialmente no acesso individual à tutela jurisdicional.

Por força desse e de outros fatores, o Poder Judiciário brasileiro, desde meados da década de 1990, passou a enfrentar um quadro crônico de congestionamento, que pode ser atribuído em grande medida à litigiosidade repetitiva. Essa afirmação se baseia em alguns dados estatísticos do Conselho Nacional de Justiça (CNJ), que se propôs a identificar os "100

\footnotetext{
15 A Lei Federal n 8.437 de 1992 proibiu que juízes de $1^{\circ}$ grau concedessem, inaudita altera parte, medidas de urgência em face do Poder Público e aprimorou mecanismos para que a medida fosse cassada pelos tribunais. A Lei Federal no 9.494 de 1997 instituiu limitações na eficácia da sentença e na imutabilidade da coisa julgada proferida em processos coletivos. A Medida Provisória $\mathrm{n}^{\circ} 2.180$ de 2011 proibiu a utilização do processo coletivo relativamente a algumas matérias de interesse do Poder Público, em especial no tocante ao direito tributário e previdenciário.

16 Destacam-se aqui o “Anteprojeto de Código Brasileiro de Processos Coletivos”, que foi elaborado por comissão capitaneada por Ada Pellegrini Grinover e entregue ao Ministério da Justiça em 2008, mas não se converteu em efetivo projeto de lei. Em seu lugar, o Ministério da Justiça elaborou um simples projeto de nova "Lei de ação civil pública", o qual foi arquivado.
} 
maiores litigantes" do Brasil. Constatou-se que 79,23 milhões de processos (num universo de aproximadamente de 83,4 milhões), ${ }^{17}$ têm em um dos seus polos um desse seleto grupo de litigantes habituais, destacando-se nesse universo os entes da Administração Pública, direta e indireta, em esferas federal, estadual e municipal (51\%), bancos (38\%) e empresas de telefonia $(6 \%)$. Esses sujeitos seriam candidatos naturais a serem réus em processos coletivos, pois se relacionam necessariamente com pluralidades indetermináveis de indivíduos. Contudo, em vez disso, tornam-se parte de milhões de processos individuais.

\section{Reformas do CPC de 1973 (1990 a 2008)}

Chega-se, por fim, ao terceiro conjunto de leis que reformaram o CPC de 1973 para efeito de melhor tratar os processos individuais.

Não se pode negar que, entre 1992 e 2008, houve uma série expressiva de leis reformadoras do CPC de 1973 que tornaram mais efetiva a prestação jurisdicional puramente individual.

Contudo, parece evidente que grande parte das reformas tinham a clara finalidade de acelerar ou aglutinar processos individuais repetitivos, com especial ênfase naqueles já pendentes em grau de recurso, sempre que a decisão judicial estivesse amparada em precedentes judiciais. ${ }^{18}$

No grupo das leis responsáveis por acelerar processos repetitivos, estão aquelas ${ }^{19}$ que substituíram julgamentos colegiados por decisões monocráticas em $2^{\circ}$ grau de jurisdição e nos tribunais superiores (rompendo-se secular tradição do direito luso-brasileiro), bem como a que permitiu a prolação julgamentos de improcedência liminar de demandas repetitivas (art. 285-A do CPC de 1973, com redação dada pela Lei nº 11.277 de 2006) e, finalmente, a que passou a limitar o cabimento de recursos em causas cujo objeto fosse questão jurídica já pacificada pelo tribunal competente (art. $518, \S 1^{\circ}$, do CPC de 1973, inserido pela Lei $\mathrm{n}^{\circ}$ 11.276/2006).

Já os mecanismos de aglutinação para gestão de recursos repetitivos - também assentados sobre precedentes judiciais - foram criados entre 2007 e $2008,{ }^{20}$ exclusivamente no âmbito dos dois principais tribunais superiores do Brasil, isto é, o Supremo Tribunal Federal (STF) e o Superior Tribunal de Justiça (STJ).

17 http://www.cnj.jus.br/images/pesquisas-judiciarias/Publicacoes/sum_exec_por_jn2010.pdf (consulta 07.08.2015); http:// www.cnj.jus.br/images/pesquisas-judiciarias/pesquisa_100_maiores_litigantes.pdf (consulta em 07.08.2015).

18 Não há, nas leis referidas na nota anterior, uma padronização. Ora o sistema se contentava com decisão proferida pelo próprio órgão em casos iguais, ora exigia "jurisprudência dominante" (isto é, um conjunto reiterado de decisões uniformes), ora se exigia a existência de "súmula".

19 Refiro-me em especial, mas não exclusivamente, às alterações introduzidas pelas Leis Federais no 8.038 de 1990, 9.756 de $1998,10.352$ de 2001, 11.276 de 2008 e 11.277 de 2008.

20 Refiro-me às alterações que as Leis Federais no 11.418 de 2007 e 11.672 de 2008 trouxeram para o CPC de 1973 no que as regras dos recursos dirigidos às Cortes de vértice. 
Tanto no âmbito do STF (para o recurso extraordinário) quanto no STJ (para o recurso especial, que visa unificar a interpretação e aplicação do direito federal infraconstitucional), criaram-se mecanismos para selecionar um ou mais "casos-piloto" e sobrestar os demais processos repetitivos. Gerado o precedente judicial apto a fixar a tese jurídica para o "casopiloto", deve ser ela reproduzida a todos os casos sobrestados.

Ou seja, o sistema processual brasileiro passou a apostar cada vez mais nos precedentes judiciais como fonte de racionalização de processos repetitivos e de promoção de isonomia (isto é, o mesmo papel que se esperava obter por meio da tutela de direitos acidentalmente coletivos).

A questão que se põe a essa altura é: esses mecanismosde aceleração e aglutinação surtiram os efeitos desejados, ao menos em termos de descongestionamento dos tribunais superiores?

Os extensos dados estatísticos atualmente disponíveis apontam indubitavelmente para a resposta negativa.

Alfredo Buzaid, que foi magistrado do STF na década de 1960, se queixava da excessiva carga de trabalho a que aquela Corte se achava submetida à época (cerca de 6.000 processos por ano, distribuídos entre os seus onze membros). ${ }^{21}$ Às vésperas da promulgação da Constituição Federal de 1988 (que reduziu substancialmente o rol de competências do STF), essa quantidade havia triplicado (18.674 processos por ano). Em 2007, o número anual de processos que chegaram ao STF atingiu seu ápice histórico (112.938), a demonstrar que não vinham surtindo efeito as reformas processuais calcadas na aceleração realizadas entre 1990 e 2006. Apenas a partir de 2008 é que constata queda substancial no número de processos recebidos pelo STF, sendo inevitável relacionar tal redução à técnica de aglutinação acolhida a partir de 2007. Contudo, a partir de 2012 o número de processos dirigidos ao STF voltou a subir, sinalizando que essas últimas reformas tiveram efeito meramente paliativo. ${ }^{22}$

Situação similar se verifica no âmbito do segundo mais importante tribunal de vértice do sistema judiciário brasileiro, o Superior Tribunal de Justiça (STJ). Criado pela Constituição Federal de 1988 para absorver parte das competências do STF, o STJ (integrado por 33 magistrados) recebeu 23.368 processos em 1991. Após série ininterrupta de aumentos no número de processos, chegou-se a um recorde histórico (até então) de 347.426 processos recebidos (em 2009), reforçando-se o entendimento de que os meios aceleratórios implantados nas reformas de 1990 a 2006 não implicaram diminuição do volume de trabalho daquela Corte. Acresça-se que também no STJ se pode reconhecer, a partir do início da vigência da técnica de aglutinação, queda apenas transitória do número de processos (entre 2009 e 2011)

21 A crise do Supremo Tribunal Federal. In: Estudos de direito. São Paulo: Saraiva, 1972, p. 121-180.

22 Dados extraídos do portal virtual do STF: http://www.stf.jus.br/portal/cms/verTexto.asp?servico=estatistica\&pagina= movimentoProcessual (consulta em 23.07.2015). 
pois, ao final de 2014, já se havia atingido um número de processos superior ao do recorde histórico anteriormente verificado (386.423). ${ }^{23}$

Assim, pode-se dizer que o funcionamento dos dois principais tribunais de vértice no Brasil está há muito completamente inviabilizado, muito distante do que seria recomendável para o adequado desempenho de seus respectivos papéis constitucionais.

Ademais, os números relevam o fracasso do modelo de aceleração / aglutinação de processos repetitivos individuais, cujo funcionamento é fundamentalmente baseado em precedentes judiciais.

É possível afirmar que essa realidade não chegou a ser levada em conta quando o atual CPC de 2015 começou a ser gestado (o Senado Federal designou uma Comissão de Juristas para elaboração do Anteprojeto em outubro de 2009, a qual concluiu a elaboração do texto básico que viria a ser convertido no Código em junho de 2010).

A impressão que se tem é que, naquela época, ainda impressionavam os primeiros números que indicavam que as reformas processuais de 2007 e 2008 realmente haviam reduzido o congestionamento dos dois principais tribunais superiores. Àquele tempo não se havia notado que se tratava, apenas, de um pequeno "alívio" transitório, e ainda não havia sido retomado o aumento no número de processos recebidos anualmente por ambos os tribunais.

Foi com base em uma certa "ilusão" de uma situação meramente transitória que se fixaram as balizas principais do CPC de 2015, que foram pouco corrigidas durante os seus mais de cinco anos de tramitação. Esse é, portanto, o cenário para começar a examinar parte das principais alterações estruturais do CPC de 2015 em relação ao CPC de 1973.

\section{CPC de 2015 e litigiosidade repetitiva}

Uma parte expressiva das principais novidades introduzidas pelo CPC brasileiro de 2015 representa o aprofundamento das tendências sinalizadas nas reformas processuais operadas de 1992 em diante: enfraquecimento do processo coletivo (que continua a ser tratado em um microssistema apartado do Código) e aprimoramento / ampliação de técnicas de aceleração / aglutinação de processos repetitivos individuais por meio da valorização da eficácia normativa de precedentes judiciais.

De fato, além de consolidar e aprimorar as técnicas de aceleração introduzidas pelas reformas ao CPC de 1973, o CPC de 2015 ampliou os poderes do juiz de $1^{\circ}$ grau quando do recebimento da demanda, sempre que ela versar sobre questão já assentada em precedente judicial. Se a pretensão do autor é contrária à tese firmada em determinadas modalidades de

23 Dados extraídos do portal virtual do STJ: http://www.stj.jus.br/webstj/Processo/Boletim/?vPortalAreaPai=183\& vPortalArea $=584$ (consulta em 23.07.2015). 
precedentes judiciais, o juiz de $1^{\circ}$ grau poderá julgá-la improcedente liminarmente (art. 332). Se, por outro lado, a pretensão do autor se alinha a determinadas modalidades de precedente e houver comprovação documental de que sua situação permite a incidência da tese jurídica lá firmada, o juiz pode conceder provimento antecipatório de tutela independentemente de alegação de urgência (art. 311, II).

De outra parte, o CPC de 2015, além de aperfeiçoar os mecanismos de gestão de recursos repetitivos nos tribunais de vértice, estendeu a mesma técnica para os tribunais de $2^{\circ}$ grau. Trata-se do chamado "Incidente de Resolução de Demandas Repetitivas" (IRDR), que visa selecionar "causas-piloto" e suspender todos os processos (individuais e coletivos) ${ }^{24}$ repetitivos. Fixada a tese, ela há de ser reproduzida de forma "vinculante" por todos os juízes sujeitos hierarquicamente ao respectivo tribunal.

Num balanço crítico, ocorre dizer que o sistema de "tratamento coletivo de demandas individuais repetitivas" - que passou a ser implementado pelas reformas processuais dos anos 1990-2000 e foi decididamente abraçado pelo CPC de 2015 - apresenta ao menos sete graves problemas em comparação com o sistema de tutela coletiva: (a) lida-se com o efeito (multiplicidade de processos) e não com a causa (litígios de massa originalmente levados ao Poder Judiciário de maneira atomizada, em processos individuais, tal como o médico que combate apenas a febre, em vez de tratar da infecção); (b) o foco desses mecanismos de aglutinação é a solução do problema do Poder Judiciário (e não do conflito de massa, que pode ter sido judicializado apenas por uma ínfima parte dos indivíduos atingidos); ${ }^{25}$ (c) comprometese a representatividade adequada da coletividade a ser atingida pela decisão proferida no "caso-piloto", no qual há o combate desigual do litigante individual eventual versus litigante habitual;26 (d) o ordenamento não estabelece critérios para escolha dos "casos-piloto"; (e) a decisão proferida no âmbito dos incidentes de aglutinação se aplicam pro et contra a pluralidade de sujeitos titulares de direitos individuais homogêneos (contrariando uma escolha que havia sido feita no CDC no tocante à ação coletiva de tutela dos direitos individuais homogêneos e, portanto, instaurando uma evidente contradição no sistema); (f) ao julgar o incidente de aglutinação, o tribunal considerará as circunstâncias fáticas presentes no "caso-piloto" para resolver a questão jurídica de modo que sem uma adequada e profunda fundamentação, haverá uma enorme dificuldade de replicar a decisão nos casos sobrestados; (g) o incidente não elimina

24 Eis aqui mais uma evidência do enfraquecimento do processo coletivo, que passará a ser tratado sem nenhuma distinção em relação a processos individuais para efeito de julgamento de "casos-piloto". Eis aqui, penso, um retrocesso manifesto.

25 Nessa linha, há que se ponderar o risco de o Poder Judiciário valer-se de mecanismo (consciente ou inconsciente) de autoproteção para julgar contra os interesses da massa indeterminável de indivíduos, de modo a evitar que aqueles que ainda não tiverem proposto suas demandas se animem a fazê-lo à luz de um precedente vinculante favorável.

26 Aliás, sempre se considerou como premissa do sistema de tutela coletiva a provável incapacidade técnica e econômica do cidadão individualmente considerado para defender em juízo direito de caráter transindividual. Esse risco de déficit de representatividade adequada pode não ser suficientemente sanado pela possibilidade de intervenção de pessoas físicas e 
o trabalho dos magistrados perante os quais haja processos sobrestados, que deverão aplicar a decisão e expor-se a meios de impugnação quanto a essa operação.

\section{Conclusão}

À vista de tais argumentos, não tenho dúvidas em afirmar que a litigiosidade de massa tenderia a ser solucionada de forma muito mais eficaz por meio do processo coletivo, em comparação com os mecanismos de tratamento coletivo de processos individuais fundados em precedentes judiciais. Até porque os ordenamentos da família da common law, a quem se deve a criação de um sistema de precedentes vinculantes, jamais pretendeu utilizá-los como ferramenta de tratamento de litigiosidade repetitiva. ${ }^{27}$

Só o tempo dirá se o tom que permeia este brevíssimo ensaio será de pessimismo ou de realismo.

\section{Referência bibliográficas}

BARBOSA MOREIRA, José Carlos. A ação popular do direito brasileiro como instrumento de tutela jurisdicional dos chamados 'interesses difusos'. In: Temas de direito processual: primeira série. São Paulo: Saraiva, 1977, p. 110-124.

. A legitimação para a defesa dos ‘interesses difusos’ no direito brasileiro. In: Temas de direito processual: terceira série. São Paulo: Saraiva, 1984, p. 183-192.

BUZAID, Alfredo. A crise do Supremo Tribunal Federal. In: Estudos de direito. São Paulo: Saraiva, 1972, p. 121-180.

CAVALCANTI, Marcos. Incidente de resolução de demandas repetitivas e ações coletivas. Salvador: Juspodivm, 2015.

CONSELHO NACIONAL DE JUSTIÇA. Justiça em números 2010. Disponível em: http:// www.cnj.jus.br/images/pesquisas-judiciarias/Publicacoes/sum_exec_por_jn2010.pdf. Acesso em: 07.08.2015.

jurídicas (especialmente entes de classe como sindicatos e associações) para ampliação do contraditório na formação de uma decisão apta a atingir uma pluralidade indeterminável de sujeitos (esses intervenientes são denominados pelo art. 138 do CPC de 2015 de amici curiae). Isso porque os poderes dos amici curiae são limitados em comparação aos da parte e sua intervenção (que embora possa ser provocada, no mais das vezes será espontânea) não é obrigatória para validade da decisão a ser proferida.

27 Essa importância advertência foi feita por Dierle Nunes e Alexandre Melo Franco Bahia: "o sistema de uso de precedentes se estruturou historicamente muito anteriormente ao (e, pois, totalmente à revelia do) surgimento da nominada litigiosidade repetitiva" (Precedentes no CPC-2015: por uma compreensão constitucionalmente adequada do seu uso no Brasil,p.2. Disponível em:https:/www.academia.edu/12103940/Precedentes_no_CPC-2015_por_uma_compreens\%C3\%A3o_constitucionalmente_ adequada_do_seu_uso_no_Brasil, consulta em 23.07.2015). 
100 maiores litigantes. Disponível em: http://www.cnj.jus.br/images/pesquisasjudiciarias/pesquisa_100_maiores_litigantes.pdf. Acesso em: 07.08.2015.

DINAMARCO, Cândido Rangel. Instituições de direito processual civil. Vol. 1. $6^{\text {a }}$ ed. São Paulo: Malheiros, 2013.

GRINOVER, Ada Pellegrini. Direito processual coletivo. In: LUCON, Paulo Henrique dos Santos (coord.). Tutela coletiva. São Paulo: Atlas, 2006, p. 302-308.

. Novas tendências na tutela jurisdicional dos interesses difusos. In: $O$ processo em sua unidade - II. Rio de Janeiro: Forense, 1984, p.88-121.

LEONEL, Ricardo de Barros. Manual do processo coletivo. São Paulo: RT, 2002.

LIEBMAN, Enrico Tullio. Istituti del diritto comune nel processo civile brasiliano. In: CARNELUTTI, Francesco. Studi in onoredi Enrico Redenti, nel XL anno del suo insegnamento. Vol. 1. Milão: Giuffrè, 1951, p. 581-607.

NUNES, Dierle Nunes; BAHIA, Alexandre Melo Franco. Precedentes no CPC-2015: por uma compreensão constitucionalmente adequada do seu uso no Brasil. Disponível em: https://www. academia.edu/12103940/Precedentes_no_CPC-2015_por_uma_compreens\%C3\%A3o_ constitucionalmente_adequada_do_seu_uso_no_Brasil. Acesso em: 23.07.2015.

VIGORITI, Vicenzo. Interessi collettivi e processo: la legittimazione ad agire. Milão: Giuffrè, 1979. WATANABE, Kazuoet al. Código brasileiro de defesa do consumidor comentado pelos autores do anteprojeto. $8^{\mathrm{a}}$ ed. Rio de Janeiro: Forense Universitária, 2005.

ZAVASCKI, Teori Albino. Processo coletivo. São Paulo: RT, 2006.

SOBRE O AUTOR:

\section{Heitor Vitor Mendonça Sica}

Professor Associado de Direito Processual Civil da Faculdade de Direito da Universidade de São Paulo. Livre-docente em direito processual civil pela Universidade de São Paulo (2016). Vice-diretor de ensino do Instituto Brasileiro de Direito Processual. Membro do Instituto Iberoamericano de Direito Processual.

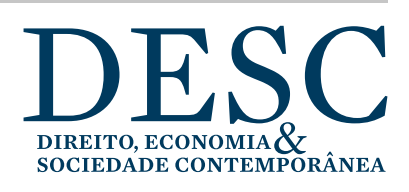

